\title{
Age-dependent changes in body composition in postmenopausal Japanese women: relationship to growth hormone secretion as well as serum levels of insulin-like growth factor (IGF)-I and IGF-binding protein-3
}

Toshitsugu Sugimoto, Daiki Nakaoka, Masamichi Nasu, Michiko Kanzawa, Takeshi Sugishita and Kazuo Chihara

Third Division, Department of Medicine, Kobe University School of Medicine, 7-5-1 Kusunoki-cho, Chuo-ku, Kobe 650, Japan

(Correspondence should be addressed to T Sugimoto)

\begin{abstract}
The present study was performed to investigate the age-dependent changes in body composition and the possible role of growth hormone (GH), insulin-like growth factor (IGF)-I and IGF-binding protein-3 (IGFBP-3) in these changes in postmenopausal Japanese women. A total of 161 Japanese women aged 45-88 years (mean 62) were enrolled in the cross-sectional study. Body composition (bone mineral content (BMC), lean body mass (LBM) and fat) was measured by dual-energy X-ray absorptiometry, and the percentage of BMC, LBM and fat was calculated by dividing each absolute value of body composition by total body mass. Urinary GH concentration divided by creatinine in nocturnal urine samples collected just after waking was used as an index of endogenous GH secretion. Serum levels of IGF-I and IGFBP-3 were measured by RIA. Urinary GH levels as well as serum levels of IGF-I and IGFBP-3 declined with age. BMC, \%BMC and LBM also declined with age, while fat mass and \%fat did not obviously change with age. Urinary GH levels as well as serum levels of IGF-I and IGFBP-3 correlated positively with BMC, even if age was taken into account. On the other hand, urinary GH correlated negatively with fat and \%fat. In contrast, serum levels of IGF-I and IGFBP-3 correlated positively with fat and \%fat. LBM did not correlate with either urinary GH or serum IGFBP-3 levels but exhibited a weakly positive correlation with serum IGF-I level. The present study suggests that the GHIGF-I-IGFBP-3 axis positively regulates bone mass, and that GH and IGF-I-IGFBP-3 inversely regulate fat mass, i.e. GH negatively and IGF-I-IGFBP-3 positively regulates it.
\end{abstract}

European Journal of Endocrinology 138 633-639

\section{Introduction}

It is well known that aging causes changes in body composition such as a decrease in bone mass (1). Growth hormone $(\mathrm{GH})$ secretion rate as well as serum levels of insulin-like growth factor (IGF)-I, an anabolic factor for bone (2), and IGF-binding protein-3 (IGFBP3 ), a modulator of IGF action (2), all decrease with age (3). Most of the IGF-I in the serum is believed to be generated from the liver, and its concentration depends on the amount of $\mathrm{GH}$ secreted, except in certain conditions such as malnutrition, liver dysfunction and GH receptor abnormality (4). Circulating IGF-I is bound mainly to IGFBP-3, and serum IGFBP-3 level is reported to be positively regulated by GH and/or IGF-I (5-7). Although several lines of evidence have suggested that GH plays an important role in the maintenance of bone mass in adults $(3,8,9)$, it remains unclear whether the GH-IGF-I-IGFBP-3 axis is actually responsible for the age-dependent decrease in bone mass. The recent development of dual-energy X-ray absorptiometry
(DXA) has enabled us to analyze body composition in terms of lean body mass (LBM) and fat mass easily and precisely (10). Our previous study showed that DXA is useful for the analysis of age- and sex-dependent changes in body composition (11). The present study aimed to examine the age-dependent changes in body composition in postmenopausal Japanese women with special reference to the possible roles of GH, IGF-I and IGFBP-3.

\section{Subjects and methods}

\section{Subjects}

A total of 161 postmenopausal Japanese women aged 45 to 88 years (mean 62) participated in this study and gave informed consent. The study was approved by the institutional review board of our institution. All the women had been without spontaneous menses for over a year. Serum estradiol was less than $20 \mathrm{pg} / \mathrm{ml}$. No 

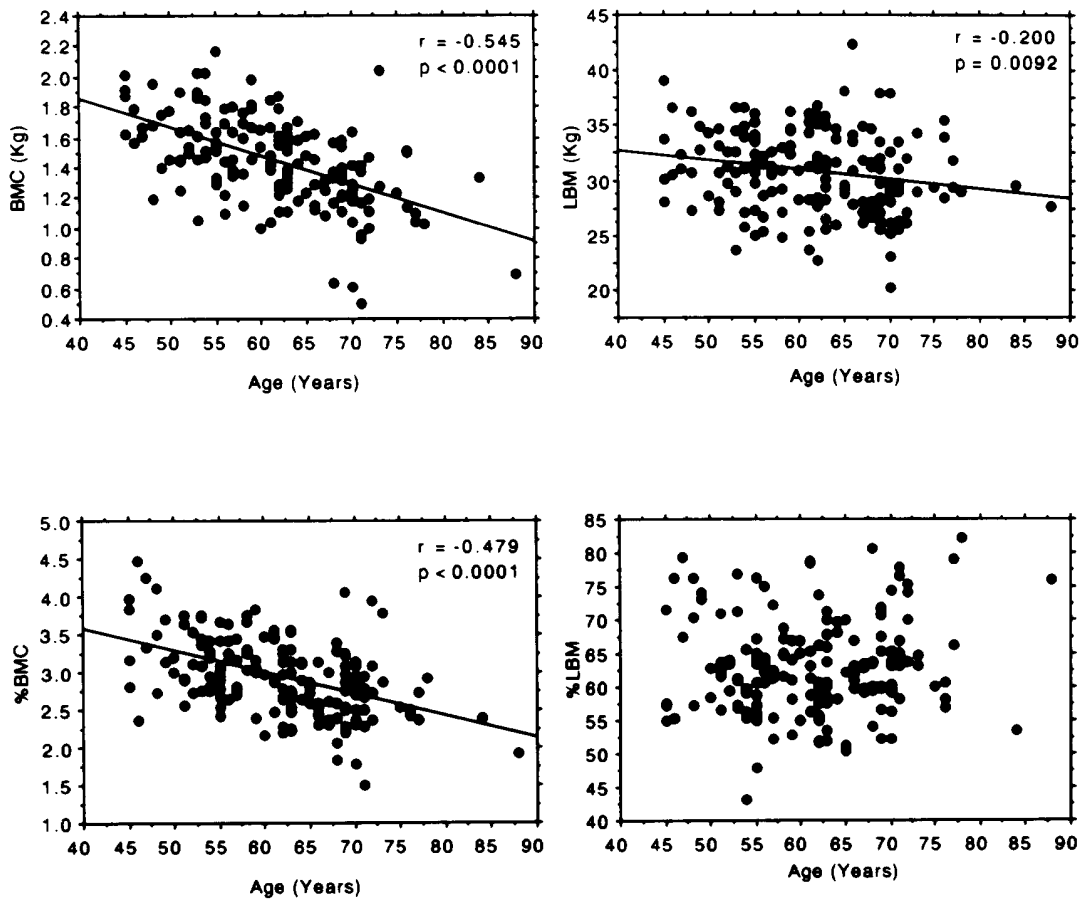

Figure 1 Changes in body composition with age. The percentage of BMC, LBM and FAT were calculated by dividing each absolute value of body composition by total body mass and expressed as \%BMC, \%LBM and \%FAT.

subject had hepatic or renal dysfunction or nutritional derangements that might cause changes in body composition. None were taking drugs known to influence bone metabolism and body composition before the time of the study.

\section{Measurement of body composition}

Bone mineral content (BMC), LBM and fat mass were measured by DXA (QDR-2000 Hologic Inc, Boston, MA, USA) using whole-body absorptiometry software and expressed in $\mathrm{kg}$. Percentage BMC, LBM and fat mass were calculated by dividing each absolute value of body composition by total body mass. Percentage trunk fat was calculated by dividing trunk fat mass by total fat mass and was designated \%trunk fat. The same operator tested all the women during the study to eliminate operator discrepancies. A strong correlation between body weight and total body mass measured by DXA $(r=0.98)$ was obtained in a preliminary study. Coefficients of variation of measurements of BMC, LBM and fat mass were $0.9,1.0$ and $2.0 \%$ respectively.

\section{Biochemical measurements}

Since the main daily GH peak occurs in adults during the early nocturnal phase of sleep, urine was collected just after waking in the morning on three days. There
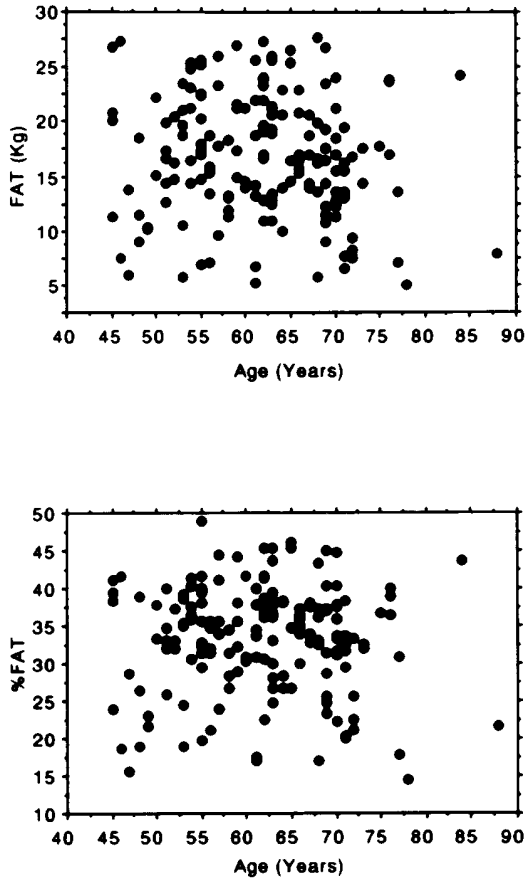

is considerable day to day variation; therefore the mean of three GH concentrations divided by creatinine was used as an index of endogenous $\mathrm{GH}$ secretion. Urinary GH was measured by a sandwich enzyme immunoassay $(12,13)$, and the coefficient of variation defined over the range $3.4-36 \mathrm{ng} / \mathrm{l}$. Intra-assay and interassay variations of this measurement were 6-8 and $9-10 \%$ respectively. After overnight fasting, serum was collected. Serum was promptly separated and stored at $-20^{\circ} \mathrm{C}$ until assay. Serum IGF-I was measured by RIA after acid-ethanol extraction (14, 15). Serum IGFBP-3 was also measured by RIA (5). The coefficients of variation for serum IGF-I and IGFBP-3 levels were defined over the range 10-1000 and $0.625-10 \mathrm{ng} / \mathrm{ml}$ respectively. Intra-assay and interassay variations of these measurements were 34 and $7-8 \%$ respectively.

\section{Statistical analysis}

Regression analysis was performed using the statistical computer program Abacus Concepts Statview (Abacus Concepts Inc., Berkeley, CA, USA). Simple regression analysis was performed to assess the linear relationship between study parameters. Pearson's correlation coefficients were calculated. $P<0.05$ was considered statistically significant. In some cases, multiple regression analyses were also employed. 

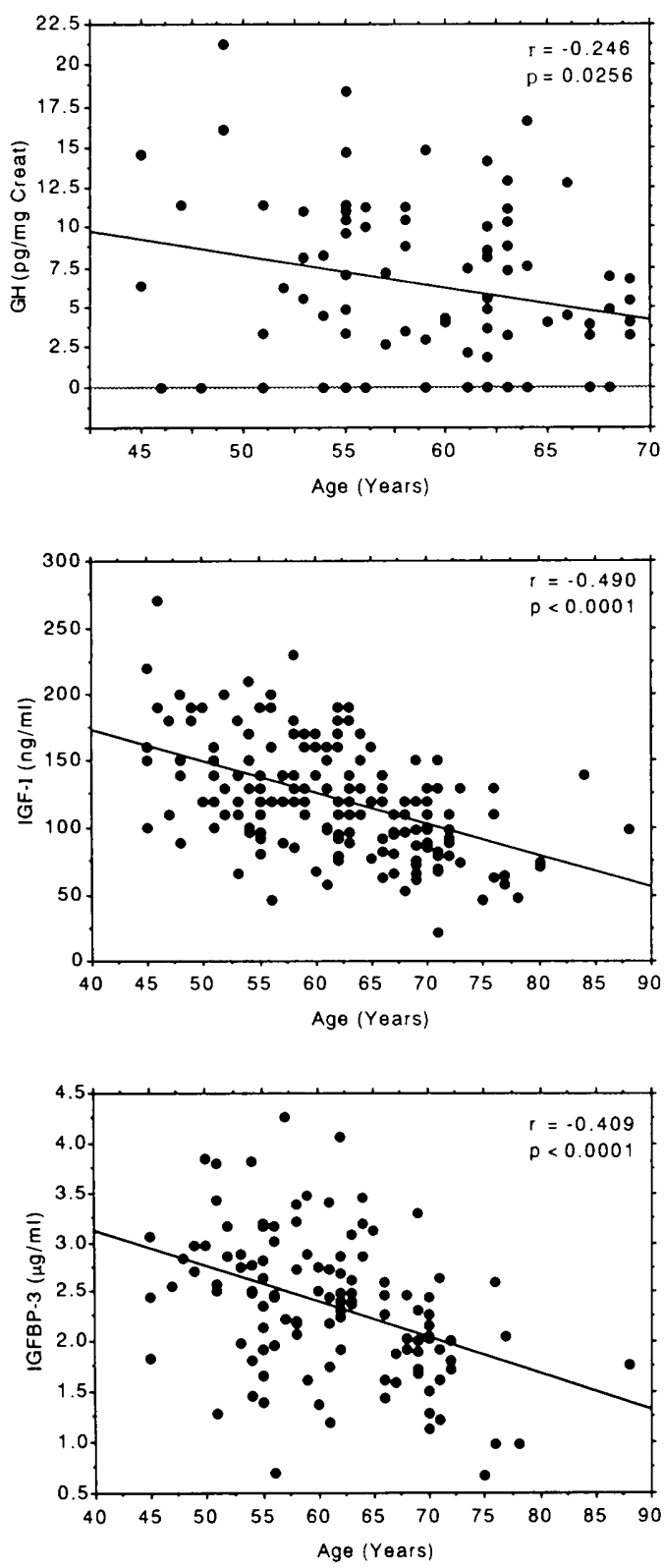

Figure 2 Age-dependent changes in urinary GH level (expressed as $\mathrm{pg} / \mathrm{mg}$ creatinine (Creat)) and serum levels of IGF-I and IGFBP-3.

\section{Results}

\section{Age-dependent changes in body composition as well as urinary GH level and serum levels of IGF-I and IGFBP-3}

Figure 1 shows changes in body composition with age in postmenopausal women. As for bone, BMC as well as $\%$ BMC clearly declined with age. On the other hand, although LBM declined to some extent with age, neither \%LBM nor fat and \%fat significantly changed with age. Figure 2 shows age-dependent decreases in urinary GH levels as well as serum levels of IGF-I and IGFBP-3.

\section{Role of GH, IGF-I and IGFBP-3 in the regulation of body composition}

Since urinary GH levels and serum levels of IGF-I and IGFBP-3 as well as BMC and \%BMC declined with age, we next examined whether the GH-IGF-I-IGFBP-3 axis was actually involved in age-dependent bone loss. As shown in Fig. 3, urinary GH and serum levels of IGF-I and IGFBP-3 correlated positively with BMC and \%BMC. Multiple regression analyses were also employed to explore further whether there is an age-independent correlation between BMC and the GH-IGF-I-IGFBP-3 axis (Table 1). Age was indeed a greater predictor of BMC; however, BMC still correlated positively with urinary GH level as well as serum levels of IGF-I and IGFBP-3, even if age was taken into account.

As shown in Fig. 4, LBM did not correlate with either urinary GH or serum IGFBP-3 levels, but exhibited a weakly positive correlation with serum IGF-I level. This correlation between LBM and serum IGF-I level was also significant, even if age was taken into account (data not shown). Serum levels of IGF-I and IGFBP-3 correlated negatively with \%LBM, whereas urinary GH correlated positively with \%LBM.

Urinary GH level correlated negatively with fat and \%fat (Fig. 5). In contrast, serum levels of IGF-I and IGFBP-3 correlated positively with fat and \%fat. All these correlations were also significant, even if age was taken into account (data not shown). As shown in Fig. 6 , urinary GH level correlated negatively with \%trunk fat, but no significant correlation was found between $\%$ trunk fat and serum levels of IGF-I or IGFBP-3.

Table 1 Multiple regression of BMC against age and GH, IGF-I or IGFBP-3. Parameter estimates are means \pm S.E.M.

\begin{tabular}{lcrrr}
\hline Dependent variable & Independent variable & Parameter estimate & $\boldsymbol{P}$ & $\boldsymbol{r}^{2}$ \\
\hline BMC & GH & $11.325 \pm 5.150$ & 0.0309 & 0.219 \\
BMC & Age & $-13.839 \pm 4.046$ & 0.0010 & \\
& IGF-I & $1.755 \pm 0.497$ & 0.0005 & 0.347 \\
BMC & Age & $-14.883 \pm 2.430$ & $<0.0001$ & 0.397 \\
& IGFBP-3 & $73.337 \pm 34.168$ & 0.0342 & 0.397
\end{tabular}

Multiple regression analyses were performed with BMC as the dependent variable, and age and GH, IGF-I or IGFBP-3 as the independent variables. 

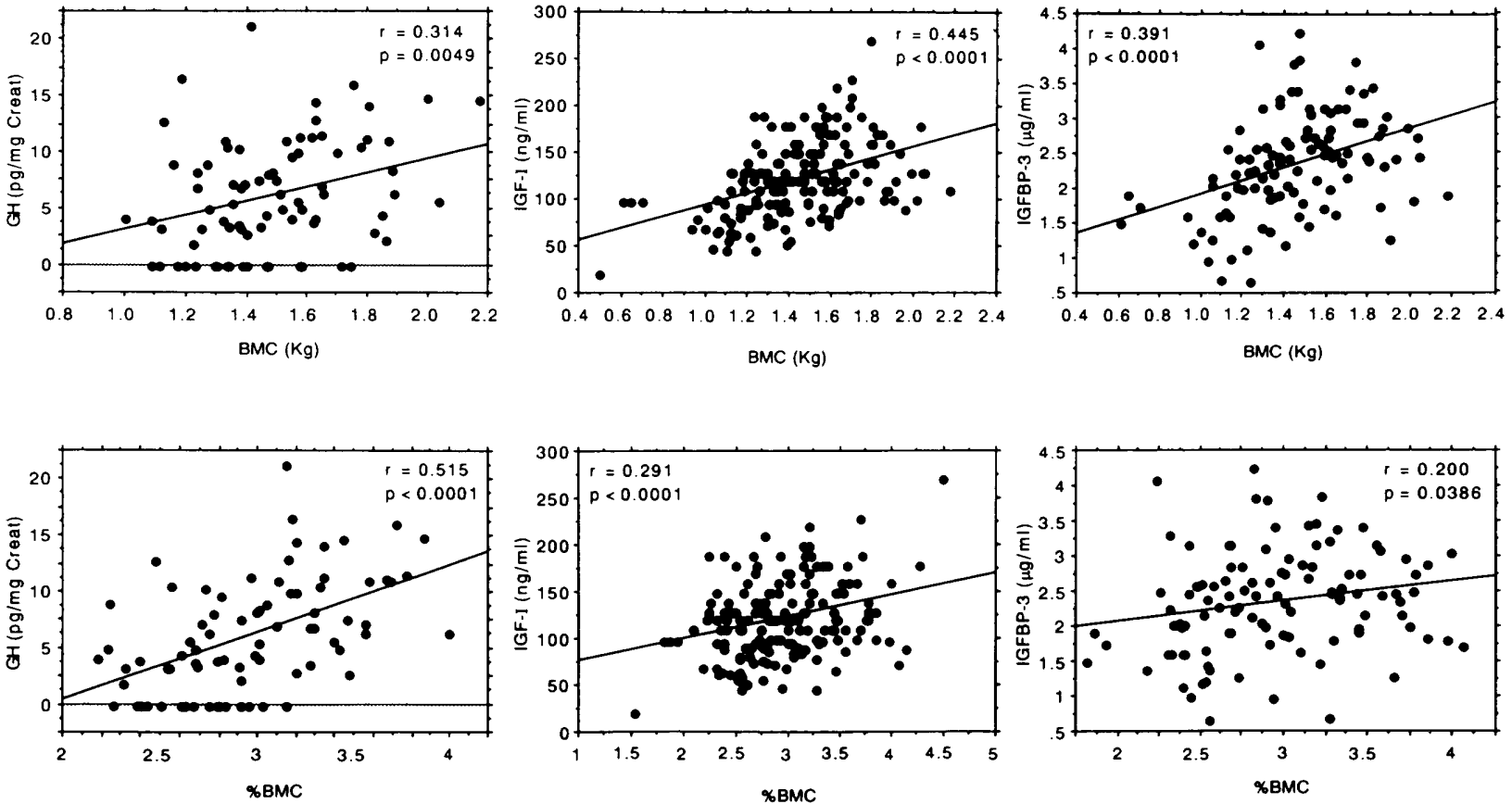

Figure 3 Relationship between BMC and urinary GH level (expressed as pg/mg creatinine (Creat)) or serum levels of IGF-I and IGFBP-3. $\% \mathrm{BMC}$ was calculated by dividing BMC by total body mass.

\section{Discussion}

It is well known that normal human aging is associated with characteristic changes in body composition, including decreases in bone mass and LBM and an increase in adiposity, which progress particularly rapidly in mid and late adulthood (1). Hydrodensitometry, skinfold thickness measurement and ${ }^{40} \mathrm{~K}$ spectrometry have been used for analysis of body composition (16). Previous studies using these methods revealed an
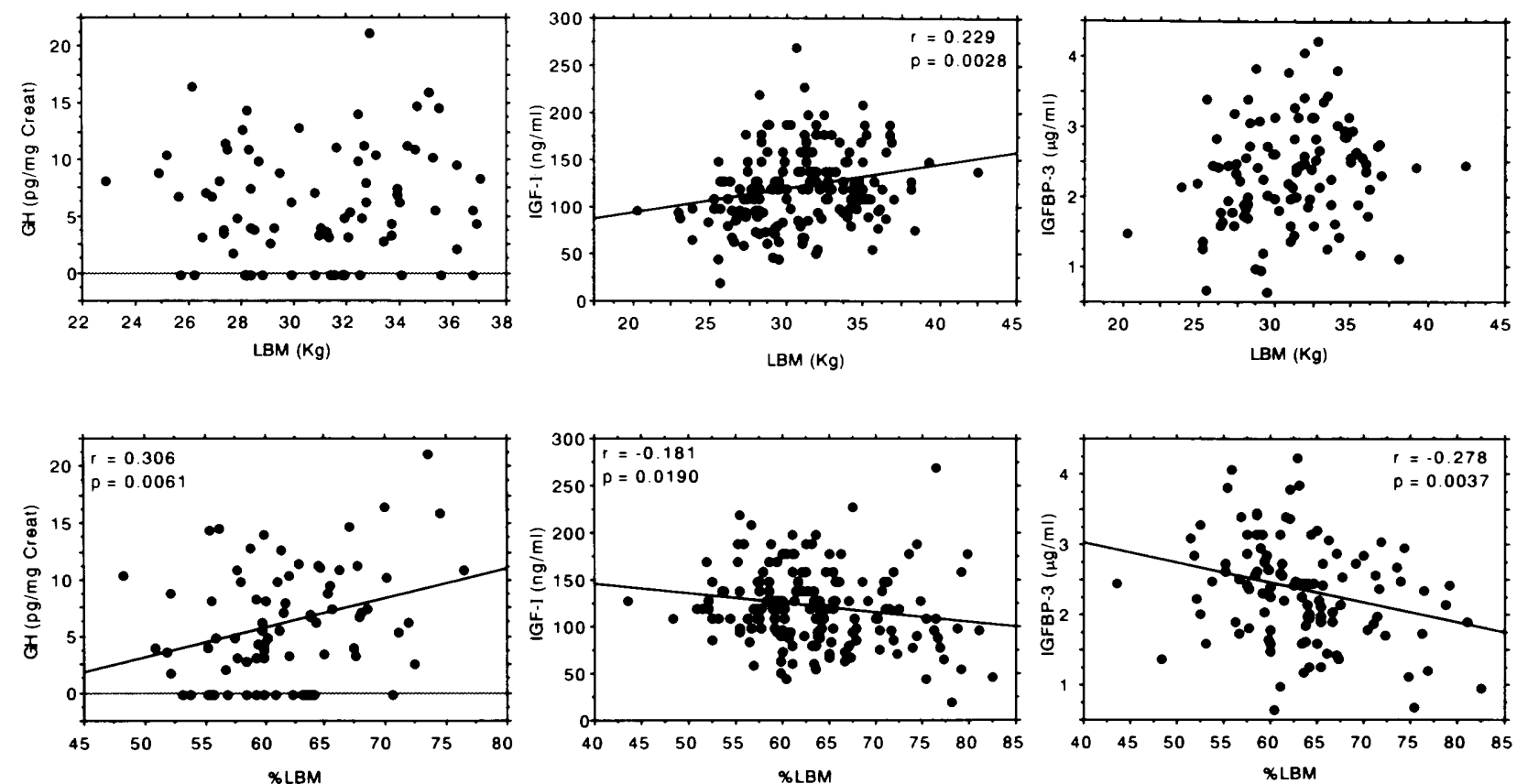

Figure 4 Relationship between LBM and urinary GH level (pg/mg creatinine (Creat)) or serum levels of IGF-I and IGFBP-3. \%LBM was calculated by dividing LBM by total body mass. 

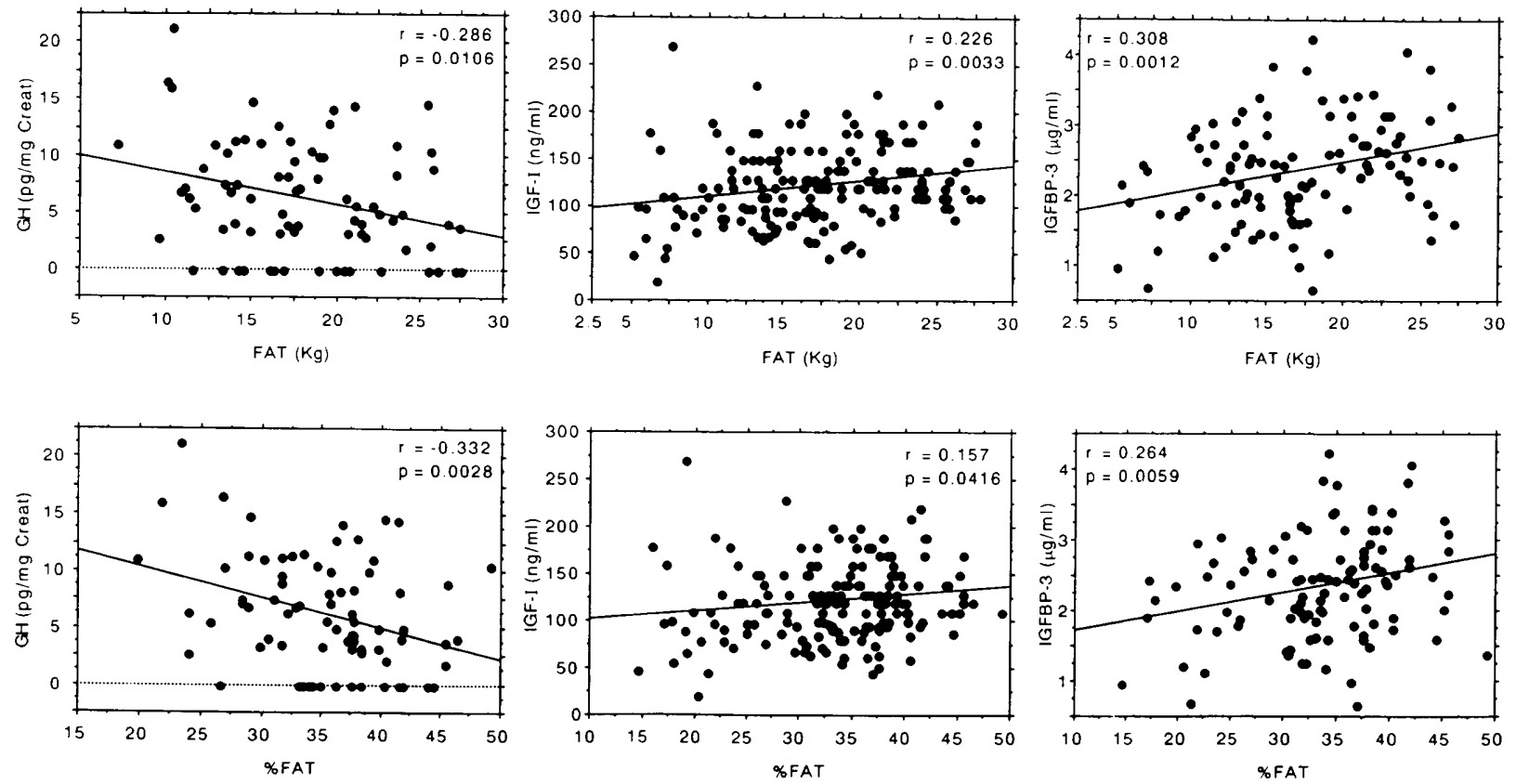

Figure 5 Relationship between fat mass and urinary GH level (expressed as pg/mg creatinine (Creat)) or serum levels of IGF-I and IGFBP-3. \%FAT was calculated by dividing fat by total body mass.

age-dependent decrease in lean mass and a reciprocal increase in fat mass $(17,18)$. The recent development of DXA has enabled us to measure body composition more precisely and easily (11). The present study using DXA revealed that BMC clearly declined and LBM declined to some extent with age in postmenopausal Japanese women, which is in agreement with our previous data using DXA (11). The present study also shows that BMC declines more extensively with age than LBM. Since LBM reflects the overall mass of skeletal muscle, skin and visceral organs, our data indicate that women lose bone mass much more rapidly than muscle and organ mass with age. On the other hand, the present and our previous studies (11) reveal that fat mass does not obviously change with age. Our data are compatible with those obtained using dual photon absorptiometry (DPA) reported by Lindsay et al. (19), although Hassager \& Christiansen (20) reported that \%fat measured by DPA increased with age in both sexes. Although we could not clarify the reason for these discrepancies, an ethnic difference in fat mass changes with age may exist.

Several lines of evidence have indicated that the measurement of GH levels in morning urine specimens is useful for the diagnosis of GH deficiency, since urinary $\mathrm{GH}$ excretion grossly reflects endogenous GH secretion $(21,22)$. However, urinary GH excretion is influenced by renal tubular function $(23,24)$, and the possibility cannot be ruled out that renal tubular dysfunction may be masked in older subjects, although serum creatinine levels of all women, less than $0.9 \mathrm{mg} / \mathrm{dl}$, are presumed to be normal. Therefore, estimation of urinay GH level as an index of the endogenous rate of GH secretion was restricted to subjects younger than 70 . The present study revealed that urinary $\mathrm{GH}$ level as well as serum levels of IGF-I and IGFBP-3 declined with age, which is compatible with previous reports (3). The present findings indicate an age-dependent attenuation of the GH-IGF-I-IGFBP-3 axis in postmenopausal women.

In the present study, urinary $\mathrm{GH}$ level and serum levels of IGF-I and IGFBP-3 all correlated positively with $\mathrm{BMC}$ and \%BMC. Moreover, multiple regression analyses revealed age-independent positive correlations between $\mathrm{BMC}$ and urinary $\mathrm{GH}$ level as well as serum levels of IGF-I and IGFBP-3. The present findings suggest an important role for endogenous $\mathrm{GH}$ secretion in the maintenance of bone mass in postmenopausal women and also suggest that age-dependent suppression of the GH-IGF-I-IGFBP-3 axis may be partly involved in the age-dependent bone loss.

In our study, fat and \%fat correlated negatively with urinary GH level but positively with serum levels of IGFI and IGFBP-3. In vitro experiments with adipose tissue slices and isolated adipocytes have revealed a lipolytic action of $\mathrm{GH}$ and the presence of somatotropic receptors on the cell membrane as well as an anti-lipolytic effect of IGF-I on GH-induced lipolysis (25-28), indicating a direct antagonistic action between GH and IGF-I on the lipolytic activity of adipocytes. Taken together, the present data suggest that $\mathrm{GH}$ negatively regulates fat mass not via the IGF-I-IGFBP-3 pathway and that IGFI-IGFBP-3 positively regulates fat mass independently of GH. Since GH levels and serum levels of IGF-I and IGFBP-3 decrease with age, these counterregulatory 

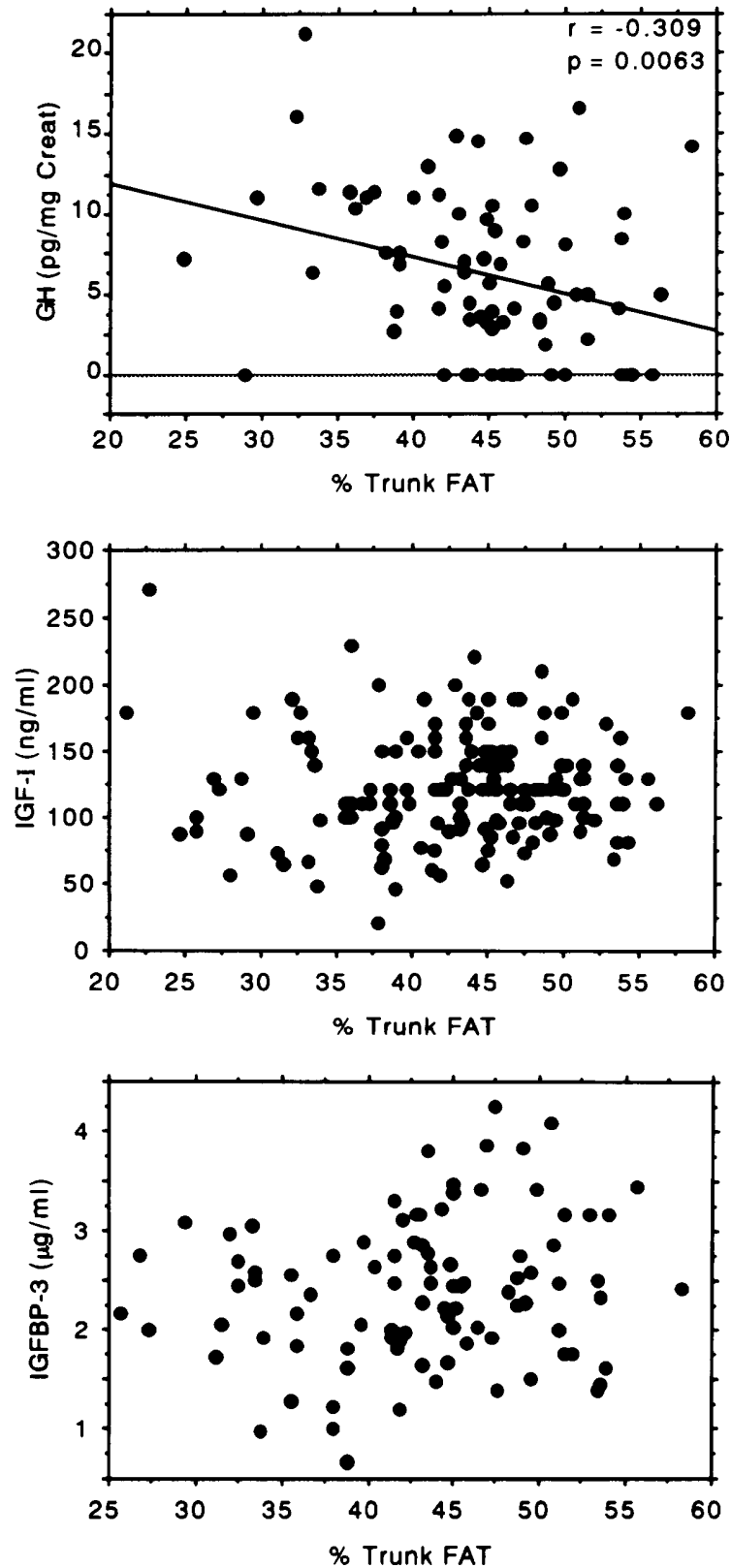

Figure 6 Relationship between \%trunk fat and urinary GH level (expressed as $\mathrm{pg} / \mathrm{mg}$ creatinine (Creat)) or serum levels of IGF-I and IGFBP-3. \%Trunk fat was calculated by dividing trunk fat mass by total fat mass.

actions of $\mathrm{GH}$ and IGF-I-IGFBP-3 on fat mass may cancel each other out and partly explain why aging does not appear to affect fat mass.

The age-related decrease in $\mathrm{GH}$ is reported to be strongly related to the proportion of abdominal body fat $(3,29)$. $\mathrm{GH}$ administration to both $\mathrm{GH}$-deficient children and adults prompted a redistribution of adipose tissue from the abdomen to the periphery and decreased lipogenesis in abdominal tissue (3, 29). In the present study, GH levels but not serum levels of IGF-I and IGFBP-3 correlated negatively with \%trunk fat. The present findings therefore suggest that the redistribution by $\mathrm{GH}$ of abdominal fat tissue is not via the IGF-I-IGFBP-3 pathway but a direct action of GH itself.

It is reported that muscle makes up $50 \%$ of LBM in young subjects, whereas half of the muscle mass has disappeared at age 75 because of reductions in both number and size of the myocytes $(1,30)$. However, the change in LBM was minimal and less prominent, compared with that in bone mass, although the agedependent decrease in LBM was statistically significant in this study. Since the shrinkage of LBM does not simply reflect atrophy of skeletal muscles but is also influenced by changes in other tissues such as skin and visceral organs, a reduction in muscle mass may be masked by changes in the other components, even if it did indeed decrease. Controversy still exists about whether GH mediates its anabolic action on muscle through IGF-I (31-34). The present study did not clarify this point, because there was a small but statistically significant correlation between LBM and serum IGF-I, but not between LBM and urinary GH. Although we found that \%LBM correlated positively with urinary GH and negatively with serum IGF-I and IGFBP-3, these changes would be secondary or the result of the effects on fat mass.

Decreases in bone and muscle mass are characteristic features of normal human aging. These changes are associated with progressive impairment of bone and muscle strength, which increases the risk of falls and bone fractures. GH deficiency causes bone loss and reduction of LBM, and correction of GH deficiency reverses this trend $(8,29)$. The present data provide additional evidence about the crucial role of the GH-IGF-I-IGFBP-3 axis in the maintenance of body composition, particularly bone mass, in postmenopausal women. In addition, natural attenuation of $\mathrm{GH}$ secretion causes expansion of the intra-abdominal adipose mass, which is known to be closely related to increased risk of arteriosclerosis. Taking all its effects together, $\mathrm{GH}$ is important for the physiological regulation and maintenance of body composition as well as metabolic function during adult life.

Subjects enrolled in the present study may not represent the general population. Consequently, assessment of larger numbers of patients from the general population and population studies are necessary to clarify the precise role of the GH-IGF-I-IGFBP-3 axis in the regulation of body composition.

In conclusion, the present study shows age-dependent changes in body composition in postmenopausal Japanese women. GH as well as IGF-I and IGFBP-3 plays an important role in the age-dependent changes in body composition. 


\section{Acknowledgements}

This work was partly supported by SRF.

\section{References}

1 Rudman D. Growth hormone, body composition and aging. Journal of the American Geriatrics Society 198533 800-807.

2 Rosen CJ, Donahue LR \& Hunter SJ. Insulin-like growth factors and bone: the osteoporosis connection. Experimental Biology and Medicine 1994206 83-102.

3 Corpas E, Harman SM \& Blackman MR. Human growth hormone and human aging. Endocrine Review 199314 20-39.

4 Schwander JC, Hauri C, Zapf J \& Froesch ER. Synthesis and secretion of insulin-like growth factor and its binding protein by the perfused rat liver: dependence on growth hormone status. Endocrinology 1983113 297-305.

5 Blum WF, Ranke MB, Kietzmann K, Gauggel E, Zeisel HJ \& Bierich JR. A specific radioimmunoassay for the growth hormone (GH)dependent somatomedin-binding protein: its use for diagnosis of GH deficiency. Journal of Clinical Endocrinology and Metabolism $1990701292-1298$.

6 Laron Z, Klinger B, Blum WF, Silbergeld A \& Ranke MB. IGF binding protein 3 in patients with Laron type dwarfism: effect of exogenous rIGF-I. Clinical Endocrinology 199236 301-304.

7 Corpas E, Harman SM \& Blackman MR. 1992 Serum IGF-binding protein-3 is related to IGF-I, but not to spontaneous GH release in healthy old men. Hormone and Metabolic Research $199224543-$ 545.

8 O'halloran DJ, Tsatsoulis A, Whitehouse RW, Holmes SJ, Adams JE \& Shalet SM. Increased bone density after recombinant human growth hormone $(\mathrm{GH})$ therapy in adults with isolated $\mathrm{GH}$ deficiency. Journal of Clinical Endocrinology and Metabolism 1993 76 1344-1348.

9 Bing-You RG, Denis M-C \& Rosen CJ. Low bone mineral density in adults with previous hypothalamic-pituitary tumors: correlations with serum growth hormone responses to GH-releasing hormone, insulin-like growth factor I, and IGF binding protein 3. Calcified Tissues International 199352 183-187.

10 Mazess RB, Barden HS, Bisek JP \& Hanson J. Dual energy X-ray absorptiometry for total-body and regional bone mineral and soft tissue composition. American Journal of Clinical Nutrition 199051 $1167-1175$

11 Tsunenari T, Tsutsumi M, Ohno K, Yamamoto Y, Kawakatsu M, Shimogaki K, Negishi H, Sugimoto T, Fukase M \& Fujita T. Ageand gender-related changes in body composition in Japanese subjects. Journal of Bone Mineral Research 19938 397-402.

12 Hashida S, Ishikawa E, Kato Y, Imura H, Mohri Z \& Murakami Y. Human growth hormone (hGH) in urine and its correlation to serum hGH examined by a highly sensitive sandwich enzyme immunoassay. Clinica Chimica Acta 1987162 229-235.

13 Okuno A, Yano K, Itoh Y, Hashida S, Ishikawa E, Mohri Z \& Murakami Y. Urine growth hormone determinations compared with other methods in the assessment of growth hormone secretion. Acta Paediatrica Scandinavica 1987337 74-81.

14 Daughaday WH, Mariz IK \& Blethen SL. Inhibition of access of bound somatomedin to membrane receptor and immunobinding sites: a comparison of radioreceptor and radioimmunoassay of somatomedin in native and acid-ethanol-extracted serum. Journal of Clinical Endocrinology and Metabolism 198051 781-788.

15 Albertsson K \& Hall K. Growth hormone treatment in short children: relationship between growth and serum insulin-like growth factor I and II levels. Journal of Clinical Endocrinology and Metabolism 198765 671-678.

16 Lukaski HC. Methods for the assessment of human body composition: traditional and new. American Journal of Nutrition $198746537-556$.
17 Flynn MA, Nolph GB, Baker AS, Martin WM \& Krause G. Total body potassium in aging humans: a longitudinal study. American Journal of Clinical Nutrition 198950 713-717.

18 Heymsfield SB, Wang J, Lichtman S, Kamen Y, Kehayias J \& Pierson Jr RN. Body composition in elderly subjects: a critical apprasial of clinical methodology. American Journal of Clinical Nutrition $1989501167-1175$.

19 Lindsay R, Cosman F, Herrington BS \& Himmelstein S. Bone mass and body composition in normal women. Journal of Bone and Mineral Research 19927 55-63.

20 Hassager C \& Christiansen C. Influence of soft tissue body composition on bone mass and metabolism. Bone $198910415-$ 419.

21 Sukegawa I, Hizuka N, Takano K, Asakawa K, Horikawa R, Hashida S, Ishikawa E, Mohri Z, Murakami Y \& Shizume K. Urinary growth hormone $(\mathrm{GH})$ measurements are useful for evaluating endogenous GH secretion. Journal of Clinical Endocrinology and Metabolism 198866 1119-1123.

22 Weissberger AJ, Ho KY \& Stuart MC. Quantification of urine growth hormone $(\mathrm{GH})$ excretion by centrifugal ultrafiltration and radioimmunoassay: appraisal of the relationship between $24 \mathrm{~h}$ urinary $\mathrm{GH}$ and mean $24 \mathrm{~h}$ serum GH levels in normal and abnormal states of GH secretion. Clinical Endocrinology 198930 687-698.

23 Hattori N, Kato Y, Murakami Y, Hashida S, Ishikawa E, Mohri S \& Imura H. Urinary growth hormone levels measured by ultrasensitive enzyme immunoassay in patients with renal insufficiency. Journal of Clinical Endocrinology and Metabolism 198866 727-732.

24 Pan FP, Stevenson JL, Donaldson DL, Levy J, Wiegmann T \& Moore WV. Correlation of urinary albumin and beta-2-microglobulin and growth hormone excretion in patients with diabetes mellitus and short stature. Journal of Clinical Endocrinology and Metabolism $199071611-617$.

25 Goodman HM. In vitro actions of growth hormone on glucose metabolism in adipose tissue. Endocrinology $196576216-225$.

26 Goodman HM \& Kostyo JL. Altered profiles of biological activity of growth hormone fragments on adipocyte metabolism. Endocrinology $1981108553-558$.

27 Gavin J, Gorden P, Roth J, Archer A \& Buell DN. Characteristics of the human lymphocyte insulin receptor. Journal of Biological Chemistry 1973248 2202-2207.

28 Pascual M, Larralde J \& Martinez JA. Insulin-like growth factor I (IGF-I) affects plasma lipid profile and inhibits the lipolytic action of growth hormone (GH) in isolated adipocytes. Life Sciences 1995 57 1213-1218.

29 Boer HD, Blok G-J \& Van Der Veen EA. Clinical aspects of growth hormone deficiency in adults. Endocrine Review 199516 63-86.

30 Jennekens FGI, Tomlinson BE \& Walton JN. Histochemical aspects of five limb muscles in old age. Journal of Neurological Science 1971 $14259-266$.

31 Turner JD, Rotwein P, Novakofski J \& Bechtel PJ. Induction of mRNA for IGF-I and IGF-II during growth hormone-stimulated muscle hypertrophy. American Journal of Physiology 1988255 E513-E517.

32 Isgaard J, Vikman NK \& Isaksson OGP. Growth hormone regulates the level of insulin-like growth factor-I mRNA in rat skeletal muscle. Journal of Endocrinology 1989120 107-112.

33 Fryburg DA, Gelfand RA \& Barrett EJ. Growth hormone acutely stimulates forearm muscle protein synthesis in normal humans. American Journal of Physiology 1991260 E499-E504.

34 Fryburg DA. Insulin-like growth factor I exerts growth hormoneand insulin-like actions on human muscle protein metabolism. American Journal of Physiology 1994267 E331-E336.

Received 1 September 1997

Accepted 2 March 1998 